\title{
In situ SEM/EDS compositional characterization of osteocytes and blood vessels in fossil and extant turtles on untreated bone surfaces; different preservational pathways microns away
}

Edwin-Alberto Cadena Corresp. 1,2 $^{1}$ Facultad de Ciencias Naturales, Grupo de Investigación Paleontología Neotropical Tradicional y Molecular (PaleoNeo), Universidad del Rosario, Bogotá,
Colombia
2 Smithsonian Tropical Research Institute, Panama City, Panama

Corresponding Author: Edwin-Alberto Cadena

Email address: edwin.cadena@urosario.edu.co

Osteocytes and blood vessels are the main cellular and tissue components of the bone tissue of vertebrates. Evidence of these soft-tissue microstructures has been widely documented in the fossil record of Mesozoic and Cenozoic turtles. However, all these studies have characterized morphologically and elementally these microstructures via isolation from the fossilized bone matrix where they were preserved or in ground sections, which could raise skepticism about the results due to potential cross-contamination or reagents effects. Fossil turtle bones from three different localities with distinct preservation environments and geological settings, including Mongolemys elegans from the Late Cretaceous of Mongolia, Allaeochelys crassesculpta from the Eocene of Germany, and a podocnemidid indet. from the Miocene of Colombia are studied here. Bone from two extant turtle species, Lepidochelys olivacea, and Podocnemis lewyana, as well as a commercial chicken Gallus gallus were used for comparisons. Scanning Electron Microscopy-Energy Dispersive Spectroscopy analyses performed directly on untreated fresh surfaces show that osteocytes-like in the fossil turtle bone are mostly composed of iron and manganese. In contrast, the in situ blood vessels-like of the fossil turtles, as well as those from the extant taxa are rich in elements typically organic in origin (carbon and nitrogen), which are absent to minimally present in the surrounding bone or rock matrix; this suggests a possible endogenous composition for these fossil structures. Also, the results presented here show that although originally both (osteocytes and blood vessels) are organic soft components of bone as evidenced in the extant turtles and chicken, they can experience completely different preservational pathways only microns away from each other in the same fossil bone. 
1 In situ SEM/EDS compositional characterization of

2 osteocytes- and blood vessels-like in fossil and extant

3 turtles on untreated bone surfaces; different

4 preservational pathways microns away.

Edwin-Alberto Cadena ${ }^{1,2}$

7

${ }^{1}$ Facultad de Ciencias Naturales, Grupo de Investigación Paleontología Neotropical Tradicional

y Molecular (PaleoNeo), Universidad del Rosario, Bogotá, Colombia

${ }^{2}$ Smithsonian Tropical Research Institute, Panama City, Panama

Corresponding Author:

14 Edwin-Alberto Cadena ${ }^{1}$

Cra 26 63b-48, Bogotá, 111221, Colombia

Email address: edwin.cadena@urosario.edu.co

\section{Abstract}

Osteocytes and blood vessels are the main cellular and tissue components of the bone tissue of vertebrates. Evidence of these soft-tissue microstructures has been widely documented in the fossil record of Mesozoic and Cenozoic turtles. However, all these studies have characterized morphologically and elementally these microstructures via isolation from the fossilized bone matrix where they were preserved or in ground sections, which could raise skepticism about the results due to potential cross-contamination or reagents effects. Fossil turtle bones from three different localities with distinct preservation environments and geological settings, including Mongolemys elegans from the Late Cretaceous of Mongolia, Allaeochelys crassesculpta from the Eocene of Germany, and a podocnemidid indet. from the Miocene of Colombia are studied here. Bone from two extant turtle species, Lepidochelys olivacea and Podocnemis lewyana, as well as a commercial chicken Gallus gallus were used for comparisons. Scanning Electron MicroscopyEnergy Dispersive Spectroscopy analyses performed directly on untreated fresh surfaces show that osteocytes-like in the fossil turtle bone are mostly composed of iron and manganese. In contrast, the in situ blood vessels-like of the fossil turtles, as well as those from the extant taxa are rich in elements typically organic in origin (carbon and nitrogen), which are absent to minimally present in the surrounding bone or rock matrix; this suggests a possible endogenous composition for these fossil structures. Also, the results presented here show that although originally both (osteocytes and blood vessels) are organic soft components of bone as evidenced in the extant turtles and chicken, they can experience completely different preservational pathways only microns away from each other in the same fossil bone. 
42 Keywords: Fossil cells, exceptional preservation, osteoblasts-like, Testudines, Deep time,

43 Mongolia, Colombia, Germany

44

45

46

47

48

49

50

51

52

53

54

55

56

57

58

59

60

61

62

63

64

65

66

67

68

69

70

71

72

73

74

75

76

77

78

79

80

81

82

83

84

85

86

87

\section{Introduction}

Bone is a complex biological tissue that characterizes extant and fossil vertebrates, and consists of a mineralized (calcium, phosphorus) and a non-mineralized (collagen and non-collagenous proteins) extracellular matrix, plus water and some lipids (Boskey \& Gehron 2013; Rey et al. 2009). Cells involved in bone tissue are osteoclasts, osteoblasts, and the most abundant of them osteocytes (Bonewald 2011). Osteocytes are embedded within the hard-mineralized component of bone throughout life (exceptions being when released by fracture or during remodeling) (Robling \& Bonewald 2020), providing them high preservation potential within fossil bones, which has been extensively documented in different clades of vertebrates (e.g., Bailleul et al. 2019; Enlow \& Brown 1956; Pawlicki \& Nowogrodzka-Zagorska 1998; Schweitzer 2011; Schweitzer et al. 2013; Surmik et al. 2019). Similar preservation of osteocytes- and blood vessels-like has also been documented in fossil turtles, showing that their preservation is independent of geologic time, paleoenvironment, lithology, lineages, and latitude (Cadena 2016; Cadena et al. 2013; Cadena \& Schweitzer 2012, 2014)

Something in common to all aforementioned studies are the analytical tools used to study and characterize these fossil bone microstructures, which include principally: 1) ground sections and observation under transmitted and polarized microscopy (Cadena \& Schweitzer 2012; Surmik et al. 2019); 2) bone demineralization using ethylenediaminetetraacetic acid (EDTA) as a chelating agent (0.5 M, pH 8.0), facilitating release the osteocytes-, blood vessels-, and any other cells- or soft-tissue fibers-like from the bone matrix for their posterior study by transmitted and/or polarized light, scanning and/or transmission electron microscopy and any coupled elemental analyzer, Raman spectroscopy, Fourier-transform infrared spectroscopy (FTIR), immunological and antibody studies (e.g., Alfonso-Rojas \& Cadena 2020; Bailleul et al. 2019, 2020; Cadena 2016; Saitta et al. 2019; Schweitzer et al. 2013; Surmik et al. 2019; Wiemann et al. 2018)

The preservation of these soft-tissue microstructures (osteocytes and blood vessels) and their potential original constituents (proteins and DNA) has been questioned and considered a consequence of microbial interactions within fossil bone and its microenvironment or even as a result of cross-contamination in the laboratory (Buckley et al. 2017; Kaye et al. 2008; Saitta et al. 2019). The 'biofilm hypothesis' as a source for soft-tissue preservation in dinosaur bones has been rigorously tested, which identified fundamental morphological, chemical and textural differences between the resultant biofilm structures and those derived from dinosaur bone, demonstrating that the recovered microstructures in the reports cited above are endogenous in origin and that the 'biofilm hypothesis' should therefore be rejected (Schweitzer et al. 2016). Issues concerning cross-contamination and replications, timing of sample collections, and reagents have also been addressed by Schweitzer et al (2019).

Compositionally, the osteocytes- and blood vessels-like from different clades of fossil vertebrates have been shown to commonly be enriched in iron (Cadena 2016; Schweitzer et al. 2014; Surmik et al. 2019; Ullmann et al. 2019), an element that has been suggested to play a key role in preserving and even masking identification of proteins in fossil tissues via Fenton

Peer) reviewing PDF | (2020:07:50649:1:0:NEW 26 Jul 2020) 
88

89

90

91

92

93

94

95

96

97

98

99

100

101

102

103

104

105

106

107

108

109

110

111

112

113

114

115

116

117

118

119

120

121

122

123

124

125

126

127

128

129

130

131

132

reactions (Schweitzer et al. 2014). Other elements typically found in these fossil bone microstructures are carbon, calcium, and silicon (Cadena 2016; Ullmann et al. 2019). At present, all these studies of elemental characterization have been conducted using SEM/EDS on isolated (post-demineralization) osteocytes- and blood vessels-like, or from polished ground sections, which implies some degree of manipulation or contact with reagents or preparation tools, potentially raising skepticism on the elemental results.

Here, I explore the in situ (directly on fresh and untreated surfaces) preservation and elemental composition of bone microstructural elements (cells and blood vessels) of fossil turtle bones from three localities which have completely different geological settings (lithological, taphonomic, and fossil diagenesis), including: 1) Gobi Desert, Mongolia, from the Late Cretaceous (late Campanian-early Maastrichtian); 2) Messel Pit, Germany, from the Eocene; and 3) La Venta fauna, Colombia, from the Miocene. Comparison samples include bone from two extant turtles and a domesticated chicken. I discuss herein the results of these analyses and the advantages of using in situ SEM/EDS for understanding preservation of cells/tissues in fossils.

\section{Materials \& Methods}

Fossil and extant samples. All the fossil and extant samples analyzed here were free of any resin, glue, or stabilizing additives since field collection. Two small pieces donated by Dr. M. Norell (American Museum of Natural History, AMNH) from a partially- articulated shell (carapace and plastron) of Mongolemys elegans (IGM-90/42) were used for this study. Specimen IGM-90/42 has been previously figured, including ground sections that show excellent preservation of osteocytes-like under transmitted light microscopy (Cadena et al. 2013, figs. 7, 9). This fossil material was collected by the AMNH and the Mongolian Academy of Sciences joint field expeditions at the Bugin Tsav locality, Gobi Desert, Mongolia, from fine-grained sandstones representing ponds deposits within the Nemegt Formation, considered to be late Campanian-early Maastrichtian ( $80 \mathrm{Ma})$ in age (Jerzykiewicz 2000, references therein).

Small isolated fragments from the carapace of an Allaeochelys crassesculpta (SMF ME 2449) were donated by Dr. K. Smith (Senckenberg Naturmuseum Frankfurt, SMF); these were collected from the well-known locality of Messel Pit, which represents volcanically-influenced lake deposits from the early-middle Eocene ( $48 \mathrm{Ma})$ (Lenz et al. 2015). Osteocytes-, blood vessels-, and collagen fibers-like from this specimen were previously described and elementally characterized by Cadena (2016, figs, 4-7).

Carapace fragments from a podocnemidid indet. specimen, (UR-CP-0043), as well as the surrounding rock matrix, were collected in 2018 directly from an excavation site (approximately $1.5 \mathrm{~m}$ from the surface) using strict aseptic techniques (nitrile gloves, face mask, wrapped in sterilized aluminum foil and kept in glass containers with silica gel for moisture control until analyses were performed). This fossil material was collected from the Repartidora locality, La Victoria Formation, middle Miocene (13.6 $\pm 0.2 \mathrm{Ma})$, Tatacoa Desert, Colombia, from what are interpreted as fluvial deposits (Cadena et al. 2020). Permits for collecting and study of the samples were granted by the Colombian Geological Survey (Radicado No 20193800017321).

Peer] reviewing PDF | (2020:07:50649:1:0:NEW 26 Jul 2020) 
133 For comparisons, two extant turtle carcasses were sampled directly in the field following the 134 same aseptic protocols used for specimen UR-CP-0043. The first corresponds to carapace 135 fragments from an individual of the sea turtle Lepidochelys olivacea (uncatalogued specimen) collected in January 2017 at the Pacific coast, Santa Elena Province, Ecuador, permit granted by Yachay Tech University. The second (uncatalogued specimen) sampled corresponds to a carcass of the side-necked turtle Podocnemis lewyana found in a sand bed of the Magdalena River, close to La Victoria village, Huila Department, Colombia, under a permit granted by the ethics committee of Universidad del Rosario (Resolución DVO005 672-CV1066) and the Colombian Autoridad Nacional de Licencias Ambientales (Technical concept $N^{\circ}$ 02263, 2019). A third sample corresponds to a femur fragment from a commercial chicken Gallus gallus obtained directly from a local market. Muscle tissue was removed and small bone fragments were cut using a sterilized scalpel and dried out at room temperature for several days.

145

Institutional abbreviations. AMNH, American Museum of Natural History, New York, USA; IGM, Geological Institute of the Mongolian Academy of Sciences, Ulaan Baatar, Mongolia; SMF ME, Senckenberg Naturmuseum Frankfurt, Germany; UR-CP, paleontological collection, Facultad de Ciencias Naturales, Universidad del Rosario, Bogotá, Colombia.

150

Scanning electron microscopy and elemental analysis (SEM/EDS). Each of the fossils, rock matrix and extant bone samples were placed between two disposable sterilized lab-weighing boats and gently hit with a rock hammer to break them into smaller pieces. Using tweezers (sterilized before every mounting process) one of the smaller pieces of broken bone was transferred to an SEM holder with adjustable screws and secured. To prevent any potential particles or dust from entering the SEM chamber, each sample was gently air cleaned before placing it in the SEM carousel. Elemental analysis was performed in combination with high resolution imaging of the bone surfaces, as well as (in some cases) the rock matrix attached to it using a scanning electron microscope coupled with an energy-dispersive X-ray spectroscopy analyzer (Phenom ProX, at the Paleontological Lab of Yachay Tech University (YTU), San Miguel de Urcuqui, Ecuador). Imaging was performed at $5 \mathrm{kV}$ using different magnification settings, and point-and-map analyses of elemental composition of selected regions or features were performed at $15 \mathrm{kV}$. At least five or more points were explored for each osteocyte- or blood vessel-like, as well as the surrounding bone matrix or rock. Quality of EDS analyses was evaluated considering only those with one million counts or higher. Full raw data is presented in Data S1.

Bone demineralization. In order to test for the occurrence and preservation of osteocytes- and blood vessels-like in some of the samples, small bone pieces of Mongolemys elegans (IGM90/42) and the podocnemidid indet. specimen (UR-CP-0043) were demineralized using disodium ethylenediaminetetraacetic acid (EDTA) $(0.5 \mathrm{M}, \mathrm{pH} 8.0$ filter-sterilized using a $0.22 \mu \mathrm{m}$ filter) as previously described (Cadena 2016; Cleland et al. 2015) for a period of five days to two weeks, or until osteocytes- and blood vessels-like were detected. Photographs of the recovered osteocytes-like were taken using a transmitted light microscope (Olympus BX-63) and a polarized light microscope (Olympus BX-53) at the paleontological lab of YTU. Some of the isolated osteocytes-like from IGM-90/42 were collected with a tip in a $1.5 \mathrm{ml}$ tube, rinsed three times with E-pure water to get rid of EDTA, being centrifuged at 1500 RPM for 2 minutes between step. A drop of the supernatant was mounted in a stub, dried out at room temperature 
179 inside in a sealed small SEM-stub box to avoid any air or dust particles interact with the sample,

180

181

182

183

184

185

186

187

188

189

190

191

192

193

194

195

196

197

198

199

200

201

202

203

204

205

206

207

208

209

210

211

212

213

214

215

216

217

218

219

220

221

222

223

224 and analyzed following the same protocol and SEM/EDS machine aforementioned.

\section{Results}

Mongolemys elegans, Late Cretaceous of Mongolia. The in situ osteocytes-like of Mongolemys elegans (IGM-90/42) under SEM exhibit a distinct contrast with the surrounding bone matrix, which is exclusive of their three-dimensional volume, and it is also different from the empty osteocytes-lacuna, which exhibits the same contrast as the bone matrix (Figs. 1A-B).

Compositionally, they are predominantly composed of iron, calcium, carbon, manganese, and minor amounts of barium and nitrogen (Figs. 1C-K; 2A; Data S2; and Fig. S1). There is no evidence of any of these elements in empty osteocyte-lacunae walls, which are composed of calcium and phosphorus, like the bone matrix (Figs. 1L-N). The isolated osteocytes-like show that iron is concentrated on their external surface and the manganese in the internal, this is clearly evident in elemental maps and a cross-line elemental profile (Figs. 1O-P; S1). Observation of some of the isolated (post-demineralization) osteocytes-like under transmitted and polarized light revealed excellent morphological preservation, with some of them emitting low-degree birefringence colors under polarized light (Fig. 3).

Allaeochelys crassesculpta, Eocene of Germany. The most abundant bone microstructures preserved in this sample are blood vessels-like and the walls that formed the HaversianVolkmann $(\mathrm{H}-\mathrm{V})$ canals; also, in some, there is evidence of very small $(2.5 \mu \mathrm{m}$ diameter $)$ structures with a striated margin which resemble the morphology of osteoblast cells (Figs. 4A-D; S2). The blood vessels-like exhibit a width of 1-3 $\mu \mathrm{m}$, with an average wall thickness of $0.2 \mu \mathrm{m}$ (Fig. 4D). Compositionally, the blood vessels-like are mainly composed of carbon and nitrogen, with minor amounts of calcium, phosphorus and iron (Figs. 2B; 4E-G; 4J-N; S2; Data S2). The bone matrix surrounding them lacks nitrogen and carbon, and it is exclusively characterized by calcium, phosphorus, and iron (Figs. 4E,I). A bone sample with rock matrix attached shows that the bone is composed of calcium, phosphorus, iron, and nitrogen, and, in contrast, the rock matrix is rich in aluminum and silicon (Figs. 2C-D; 4O-Q; Data S2).

Podocnemidid indet, Miocene of Colombia. The sample of the side-necked turtle from $\mathrm{La}$ Venta, Colombia, shows on the bone external cortex preservation of walls that formed the H-V canals, blood vessels- and osteocytes-like tightly embedded in the very homogenous bone matrix (Figs. 5A-B; 5F-G). Elementally, the blood vessels-like and $\mathrm{H}-\mathrm{V}$ canal walls are rich in carbon, nitrogen, and calcium, with minor amounts of phosphorous and silicon (Figs. 2B; 5C-D; 5H-I; Data S2). In contrast, the osteocytes-like are composed of iron, calcium, aluminum, manganese, phosphorus, and minor amounts of silicon (Figs. 2B; 5H-J; Data S2). The bone matrix lacks carbon and nitrogen, and it is constituted by calcium and phosphorus mainly (Figs. 2C; 5C, E, H). An isolated bone fragment (post-demineralization) shows some of the osteocytes-like still embedded in the matrix, varying in color from orange to black, the darker ones located closer to black, dendritic mats (Figs. 5K-M).

In situ extant turtle and chicken bone microstructures. The carapace bone fragment of the extant side-necked turtle Podocnemis lewyana shows osteocytes within lacunae (Figs. 6A-B). Their composition is rich in carbon, nitrogen, calcium, and phosphorus (Figs. 2A; 6C-D; Data 
225

226

227

228

229

230

231

232

233

234

235

236

237

238

239

240

241

242

243

244

245

246

247

248

249

250

251

252

253

254

255

256

257

258

259

260

261

262

263

264

265

266

267

268

269

270

S2). The bone matrix is relatively richer in calcium (Figs. 2C; 6C, E). The H-V canals exhibit a distinct wall and a high concentration of blood vessels and red blood cells, which are rich in carbon and nitrogen (Figs. 2B; 6F-G; S3; S4; Data S2). Similar spatial patterns and composition are shared by the bone of the extant marine turtle Lepidochelys olivacea (Figs. 2; 6H-M; Data $\mathrm{S} 2$ ), and the bone of Gallus gallus (chicken) (Figs. 2; 6N-P; Data S2).

\section{Discussion}

As previously shown (Cadena 2016; Schweitzer et al. 2014; Surmik et al. 2019; Ullmann et al. 2019), the in situ analyses presented here, concur with that iron is a very common constituent of fossil osteocytes-like, such as those found in the Late Cretaceous Mongolemys elegans and the Miocene podocnemidid indet. bone samples studied herein (Figs. 1,5). However, this composition is not always homogenous and may vary between the external and the internal layer of osteocytes-like, as shown in a broken and folded osteocyte-like from M. elegans, which exhibits richer content of manganese internally and iron externally (Figs. 1O-P). High levels of manganese were also detected in osteocytes-like from the Miocene side-necked turtle from Colombia, indicating that besides iron as initially suggested by Schweitzer et al. (2014), manganese may also be involved in the preservation of these bone microstructures in deep time. The source for this rich content of manganese seems to be from manganese oxides such as pyrolusite penetrating bone microfractures, which were found herein in some fragments of the Miocene podocnemidid indet. from Colombia (Figs. $5 \mathrm{~K}-\mathrm{M}$ ), and also has been characterized to occur in dinosaur fossil bones from the same Nemegt Formation, from which the M. elegans studied herein was collected (Owocki et al. 2016). The color variation exhibited by the fossil osteocytes-like of M. elegans and podocnemidid indet. seems to be related to enrichment of manganese, higher their manganese content darker their color. In contrast to the osteocytes of the extant turtle and chicken bone, which are rich in carbon and nitrogen (Figs. 2, 6), these elements only appear in minor amounts in fossil osteocytes-like. However, these cells exhibited a very distinct composition when compared to the surrounding bone matrix and even the wall surfaces of their osteocytes-lacunae, indicating that their mineralized preservation occurred at micro-scale inside the bone, a hypothesis that should be tested by future studies using additional tools (e.g, Raman and FTIR spectroscopy).

The blood vessels-1 and H-V canal walls-like preserved in the Eocene Allaeochelys crassesculpta from the Messel Pit and the Miocene podocnemidid indet. specimen from the La Venta not only exhibited a similar morphology, but also exhibited the same elemental composition as their corresponding tissues in extant turtle and chicken bone. (Figs. 2, 4, 5, S2, S3, S4; Data S2). In both cases (extant and fossils) being rich in carbon and nitrogen, and differing from the surrounding bone matrix which is richer in calcium and phosphorus, or the rock matrix which is rich in silicon and aluminum (without any traces of carbon, calcium, or nitrogen) which suggests that carbonates or nitrates were in the surrounding microenvironment. The in situ measurements performed on some of the preserved blood vessels-like from A. crassesculpta, exhibiting uniform fabric and thin walls of $0.2 \mu \mathrm{m}$ thickness (Fig. 4D) suggest that they are not consistent with the characteristics of biofilms, which tend to be amorphous and larger in diameter (Schweitzer et al. 2016). Blood vessels constitute one of the most promising microstructures preserved in fossil turtles for molecular paleontology studies, and future studies should focus on their molecular in situ characterization using ToF-SIMS mass spectrometry, similarly as it has been used in 
271 dinosaurs and other fossil vertebrates (Alfonso-Rojas \& Cadena 2020; Henss et al. 2013;

272 Lindgren et al. 2018; Schweitzer et al. 2019).

273

274 For the first time, I herein report the preservation of osteoblasts-like in fossil vertebrates,

275 particularly in the Messel Pit turtle A. crassesculpta. They occur as oval objects with striated

276 margins that are attached to the $\mathrm{H}-\mathrm{V}$ canals (Figs. 5B-D; S2), and thus resemble the morphology

277 and size of osteblasts observed in electron micrographs of human bone (Nakamura 2007;

278 Schmidt et al. 2002). At the same time, evidence here provided from the Miocene podocnemidid

279 indet. turtle from Colombia (Figs. 5F-J) shows that, in the same bone specimen, osteocytes- and

280 blood vessels-like that are only 20 microns away from each other are compositionally different.

281 This indicates that each microstructure went through a different preservational pathway.

282 Osteocytes-like seem to be more mineralized than blood vessels-like in these fossil samples, with

283 high amount of iron and manganese, and less organic components than blood vessels-like (Fig. 2,

284 3). In the extant bone of turtles and chicken, osteocytes and blood vessels exhibit similar

285 elemental composition under SEM/EDS, both being rich in carbon and nitrogen, which are

286 typically present in abundance within proteins (Torabizadeh 2011) (Figs. 2, 6). A similar

287 composition was detected herein in fossil blood vessels from $A$. crassesculpta and the

288 podocnemidid indet., from Colombia (Figs. 4, 5).

289

290

291

292

293

294

295

296

297

298

299

300

301

302

303

304

305

306

307

308

309

310

311

312

313

314

315

Traditionally, it has been suggested that SEM/EDS has to be performed on homogenous or polished surfaces to avoid topographic effects on EDS analyses (Goldstein et al. 2003).

However, as I showed here, such effects were negligible for the analyzed sample with composition and signal intensities being very similar in both the fossil and extant samples (Fig. 2). I therefore suggest that a more critical condition for EDS analysis on untreated samples is acquire the highest maximum count rate possible; above 1 million counts is ideal.

\section{Conclusion}

This study provided evidence that in situ analyses using a conventional technique, SEM/EDS, on untreated fresh surfaces of fossil and extant bones constitutes a protocol that should be added to the rigorous plethora of proxies and tools (e.g, those recently reviewed and summarized by Schweitzer et al., (2019)) to support and demonstrate the preservation of cells, soft-tissues and their original constituents in deep time. Furthermore, in situ analyses of fossil and extant bone samples may also help eliminate any potential skepticism of results obtained by molecular paleontology studies, because, as demonstrate here, it requires minimal sample preparation/manipulation, use of reagents, or contact with lab tools that could cause possible contamination.

\section{Acknowledgements}

I thank M. Norell, K. Smith, S. Schaal and A. Vanegas for access to samples. I also thank M.

Schweitzer for some preliminary feedback on some of the results presented here. Thanks are also extended to Yachay Tech and the Colombian Geological Survey and Ethics Committee at Universidad del Rosario for the permits to collect and analyze the samples. Thanks to P. Ullmann and another anonymous reviewer for comments that improved this manuscript. 


\section{References}

318

319

320

321

322

323

324

325

326

327

328

329

330

331

Alfonso-Rojas AF, and Cadena EA. 2020. Exceptionally preserved 'skin' in an Early Cretaceous fish from Colombia. PeerJ 8:e9479.

Bailleul AM, O'Connor J, and Schweitzer MH. 2019. Dinosaur paleohistology: review, trends and new avenues of investigation. PeerJ 7:e7764.

Bailleul AM, Zheng W, Horner JR, Hall BK, Holliday CM, and Schweitzer MH. 2020. Evidence of proteins, chromosomes and chemical markers of DNA in exceptionally preserved dinosaur cartilage. National Science Review 0. DOI:10.1093/nsr/nwz206.

Bonewald LF. 2011. The amazing osteocyte. Journal of Bone Mineral Research 26:229-238.

Boskey AL, and Gehron PR. 2013. The composition of bone. In: Rosen CJ, ed. Primer on the metabolic bone diseases and disorders of mineral metabolism: John Wiley \& Sons, Inc, 49-58.

Buckley M, Warwood S, van Dongen B, Kitchener AC, and Manning PL. 2017. A fossil protein chimera; difficulties in discriminating dinosaur peptide sequences from modern cross-contamination. Proc Biol Sci 284: 20170544. DOI.org/10.1098/rspb.2017.0544.

Cadena E. 2016. Microscopical and elemental FESEM and Phenom ProX-SEM-EDS analysis of osteocyte-and blood vessel-like microstructures obtained from fossil vertebrates of the Eocene Messel Pit, Germany. PeerJ 4:e1618.

Cadena EA, Ksepka DT, and Norell MA. 2013. New material of Mongolemys elegans Khosatzky and Mlynarski, 1971 (Testudines: Lindholmemydidae), from the Late Cretaceous of Mongolia with comments on bone histology and phylogeny. American Museum Novitates 3766:1-27.

Cadena EA, and Schweitzer MH. 2012. Variation in osteocytes morphology vs bone type in turtle shell and their exceptional preservation from the Jurassic to the present. Bone 51:614-620.

Cadena EA, and Schweitzer MH. 2014. A pelomedusoid turtle from the Paleocene-Eocene of Colombia exhibiting preservation of blood vessels and osteocytes. Journal of Herpetology 48:461-465.

Cadena EA, Vanegas A, Jaramillo C, Cottle JM, and Johnson TA. 2020. A new Miocene turtle from Colombia sheds light on the evolutionary history of the extant genus Mesoclemmys Gay, 1873. Journal of Vertebrate Paleontology. DOI:10.1080/02724634.2019.1716777.

Cleland TP, Schroeter ER, Zamdborg L, Zheng W, Lee JE, Tran JC, Bern M, Duncan MB, Lebleu VS, and Ahlf DR. 2015. Mass spectrometry and antibody-based characterization of blood vessels from Brachylophosaurus canadensis. Journal of proteome research 14:5252-5262.

Enlow DH, and Brown SO. 1956. A comparative histological study of fossil and recent bone tissues. Texas Journal of Science 8:405-443.

Goldstein J, Newburry D, Joy D, Lyman C, Ehclin P, Lifshin E, Sawyer L, and Michael J. 2003. Scanning Electron Microscopy and X-Ray microanalysis: Springer Science.

Henss A, Rohnke M, El Khassawna T, Govindarajan P, Schlewitz G, Heiss C, and Janek J. 2013. Applicability of ToF-SIMS for monitoring compositional changes in bone in a long-term animal model. Journal of The Royal Society Interface 10:20130332.

Jerzykiewicz T. 2000. Lithostratigraphy and sedimentary setting of the Cretaceous dinosaur beds of Mongolia. In: Benton MJ, ed. The age of dinosaurs in Russia and Mongolia. Cambridge: Cambridge University Press, 279-296.

Kaye TG, Gaugler G, and Sawlowicz Z. 2008. Dinosaurian soft tissues interpreted as bacterial biofilms. PLoS One 3:e2808.

Lenz OK, Wilde V, Mertz DF, and Riegel W. 2015. New palynology-based astronomical and revised 40Ar/39Ar ages for the Eocene maar lake of Messel. International Journal of Earth Sciences 104:873-889.

Lindgren J, Sjövall P, Thiel V, Zheng W, Ito S, Wakamatsu K, Hauff R, Kear BP, Engdahl A, and Alwmark C. 2018. Soft-tissue evidence for homeothermy and crypsis in a Jurassic ichthyosaur. Nature 564:359-365. 
366

367

368

369

370

371

372

373

374

375

376

377

378

379

380

381

382

383

384

385

386

387

388

389

390

391

392

393

394

395

396

397

398

399

400

401

402

403

404

405

406

407

Nakamura H. 2007. Morphology, function and differentiation of bone cells. Journal of Hard Tissue Biology 16:15-22.

Owocki K, Kremer B, Wrzosek B, Krolikowska A, and Kazmierczak J. 2016. Fungal Ferromanganese Mineralisation in Cretaceous Dinosaur Bones from the Gobi Desert, Mongolia. PLoS One 11:e0146293.

Pawlicki R, and Nowogrodzka-Zagorska M. 1998. Blood vessels and red blood cells preserved in dinosaur bones. Annales of Anatomy 180:73-77.

Rey C, Combes C, Drouet C, and Glimcher MJ. 2009. Bone mineral: update on chemical composition and structure. Osteoporos International 20:1013-1021.

Robling AG, and Bonewald LF. 2020. The Osteocyte: New Insights. Annual Review of Physiology 82:485-506.

Saitta ET, Liang R, Lau MC, Brown CM, Longrich NR, Kaye TG, Novak BJ, Salzberg SL, Norell MA, Abbott GD, Dickinson MR, Vinther J, Bull ID, Brooker RA, Martin P, Donohoe P, Knowles TD, Penkman KE, and Onstott T. 2019. Cretaceous dinosaur bone contains recent organic material and provides an environment conducive to microbial communities. Elife 8:e46205.

Schmidt C, Kaspar D, Sarkar MR, Claes LE, and Ignatius AA. 2002. A scanning electron microscopy study of human osteoblast morphology on five orthopedic metals. Journal of Biomedical Materials Research 63:252-261.

Schweitzer MH. 2011. Soft tissue preservation in terrestrial Mesozoic vertebrates. Annual Review of Earth and Planetary Sciences 39:187-216.

Schweitzer MH, Moyer AE, and Zheng W. 2016. Testing the hypothesis of biofilm as a source for soft tissue and cell-like structures preserved in dinosaur bone. PLoS One 11:e150238.

Schweitzer MH, Schroeter ER, Cleland TP, and Zheng W. 2019. Paleoproteomics of Mesozoic Dinosaurs and Other Mesozoic Fossils. Proteomics 19:e1800251.

Schweitzer MH, Zheng W, Cleland TP, and Bern M. 2013. Molecular analyses of dinosaur osteocytes support the presence of endogenous molecules. Bone 52:414-423.

Schweitzer MH, Zheng W, Cleland TP, Goodwin MB, Boatman E, Theil E, Marcus MA, and Fakra SC. 2014. A role for iron and oxygen chemistry in preserving soft tissues, cells and molecules from deep time. Proceedings of the Royal Society B: Biological Sciences 281:20132741.

Surmik D, Dulski M, Kremer B, Szade J, and Pawlicki R. 2019. Iron-mediated deep-time preservation of osteocytes in a Middle Triassic reptile bone. Historical Biology. DOI.org/10.1080/08912963.2019.1599884.

Torabizadeh H. 2011. All proteins have a basic molecular formula. World Academy of Science, Engineering and Technology 54:961-985.

Ullmann PV, Pandya SH, and Ne llermoe R. 2019. Patterns of soft tissue and cellular preservation in relation to fossil bone tissue structure and overburden depth at the Standing Rock Hadrosaur Site, Maastrichtian Hell Creek Formation, South Dakota, USA. Cretaceous Research 99:1-13.

Wiemann J, Fabbri M, Yang T-R, Stein K, Sander PM, Norell MA, and Briggs DE. 2018. Fossilization transforms vertebrate hard tissue proteins into N-heterocyclic polymers. Nature Communications 9:4741.

Peer) reviewing PDF | (2020:07:50649:1:0:NEW 26 Jul 2020) 


\section{Figure 1}

Figure 1. SEM/EDS analyses of Mongolemys elegans (IGM-90/42) bone.

(A) Micrograph of one of the osteocytes-like and an empty lacuna nearby. (B) EDS of the bone region shown in (A), in which orange indicates bone matrix (calcium), and blue-yellow denotes the osteocyte-like (oxygen and iron respectively). (C) Micrograph of one osteocytelike, indicating the regions where EDS mapping and point analyses were performed. (D-E) Composite elemental map (D) and individual element maps (E) for the rectangle labeled as 1 in (C), in which osteocytes-like show high amount of iron and nitrogen. (F) Elemental point values of point 7 (bone matrix) shown in (C). (G) Elemental intensities for point 4 (osteocytelike) shown in (C). (H) Micrograph of a broken osteocyte-like inside its lacuna. (I) Individual elements maps from rectangle 1 shown in $(\mathrm{H})$, with the broken osteocyte-like showing a high content of manganese. (J) Elemental intensities for point 2 (bone matrix) shown in $(H)$. (K) Elemental intensities for point 6 (osteocyte-like) shown in (H). (L) Micrograph of a empty lacuna. (M-N) Composite elemental map and individual elements maps for the rectangle labeled as 1 in (L), in which the wall surface of the lacuna exhibits the same composition as the bone matrix. (0) An isolated, broken, and folded osteocyte-like showing a high amount of iron at its external surface and manganese in its internal region, the red line denotes the cross-line described in (P). (P) Cross-line elemental profile across the broken and folded osteocyte-like shown in (0), revealing a switch between iron and manganese content between its external and internal surfaces. Full EDS results for the points shown in $(C, H$, and L) are presented in Fig. 2 and Data S2. 
A
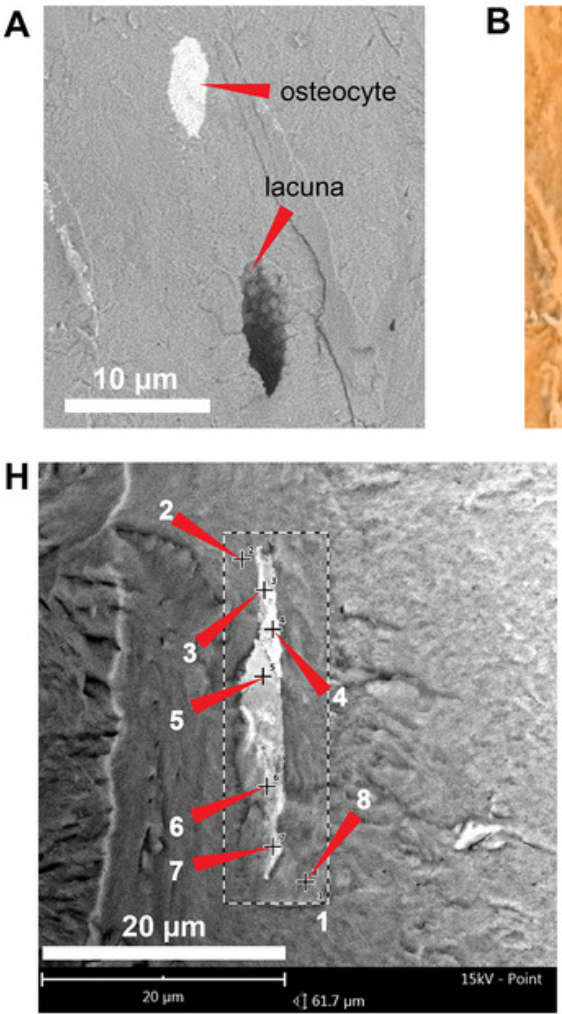

J Point 2

Element Atomic \% Weight \% Stoich. \% $\begin{array}{lrrr}\mathrm{O} & 57.33 & 48.73 & \\ \mathrm{Ca} & 12.17 & 25.92 & 28.52 \\ \mathrm{C} & 24.66 & 15.74 & 57.78 \\ \mathrm{P} & 5.84 & 9.62 & 13.7\end{array}$

\section{K Point 6}

Element Atomic \% Weight \% Stoich. $\%$ Eleme

$\begin{array}{lrrr}\mathrm{O} & 72.19 & 40.65 & \\ \mathrm{Mn} & 16.97 & 32.8 & 61.01 \\ \mathrm{Ba} & 3.49 & 16.89 & 12.56 \\ \mathrm{Ca} & 5.14 & 7.25 & 18.49\end{array}$

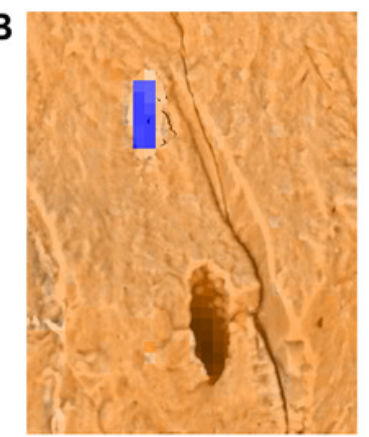

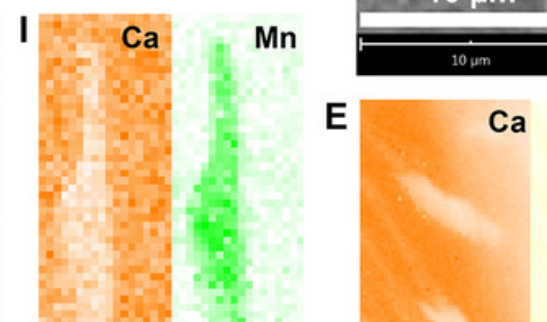
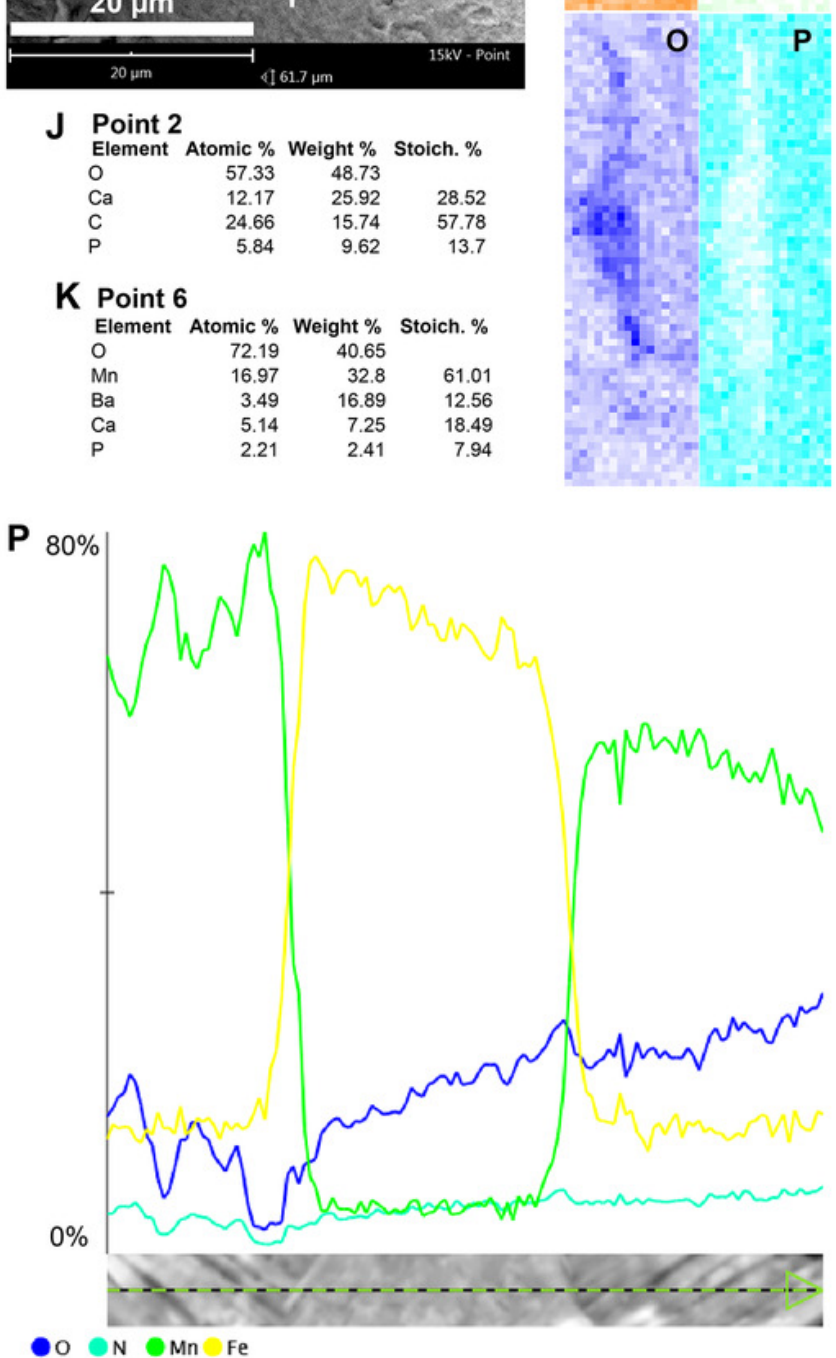

F Point 7

Element Atomic \% Weight \% Stoich. \% $\begin{array}{lrrr}\mathrm{O} & 58.9 & 49.44 & \\ \mathrm{Ca} & 16.3 & 34.26 & 39.65 \\ \mathrm{C} & 24.14 & 15.21 & 58.73\end{array}$
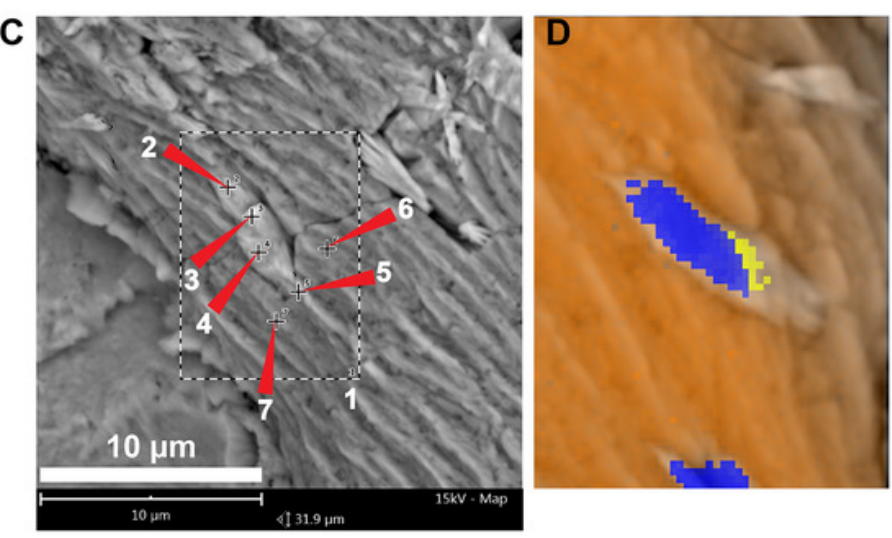
$\begin{array}{lrrr}\mathrm{C} & 24.14 & 15.21 & 58.73 \\ \mathrm{P} & 0.67 & 1.08 & 1.62\end{array}$

\section{L}

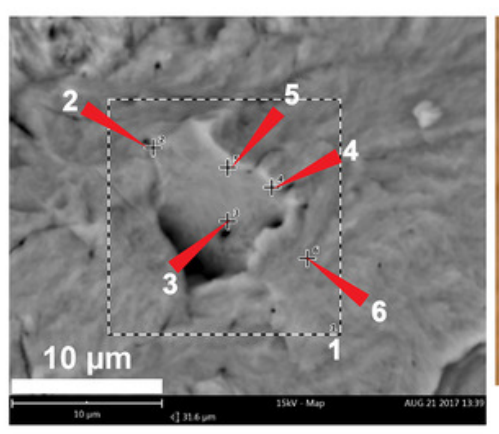

G Point 4

Element Atomic \% Weight \% Stoich. \% $\begin{array}{lll}\mathrm{Fe} & 19.94 & 39.09 \\ \mathrm{O} & 58.72 & 32.98\end{array}$ $\begin{array}{llll}\mathrm{Ca} & 58.72 & 32.98 & \\ \mathrm{P} & 15.72 & 22.11 & 38.07\end{array}$ $\begin{array}{lrrr}\mathrm{P} & 3.33 & 3.62 & 38.07 \\ & & & \\ \end{array}$

N

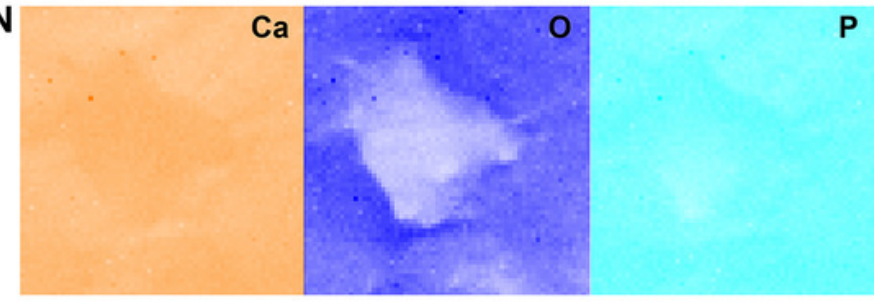

0

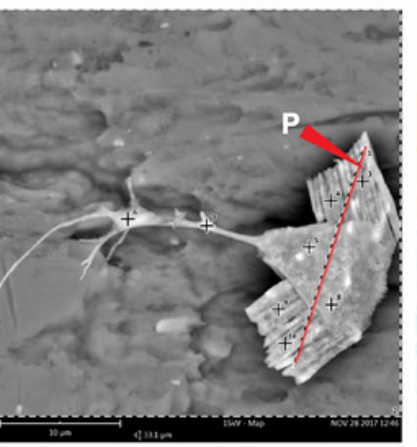

$\mathrm{Fe}$

Mn
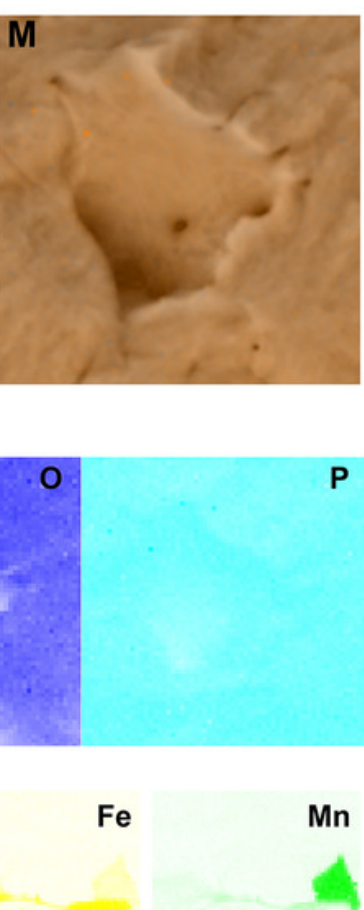

N

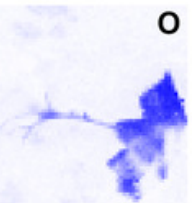




\section{Figure 2}

Figure 2. \%Wt of elements for fossil and extant turtle bone

(A) EDS point analyses of osteocytes, indicating high amounts of iron and manganese in the fossil cells (from Mongolemys elegans and the podocnemidid indet. specimens), whereas carbon and nitrogen dominate the cells from extant taxa (Podocnemis lewyana and Lepidochelys olivacea), including those from a chicken (Gallus gallus). (B) EDS point analyses of blood vessels, with fossil and extant showing a similar elemental composition rich in carbon and nitrogen. (C) EDS point analyses of the bone matrix surrounding osteocytes or blood vessels. Note how fossil and extant samples exhibit similar \%Wt values for calcium, carbon, and phosphorus. Fossils show relative enrichment in iron and a lower amount of nitrogen in comparison to the extant bone matrix samples. (D) EDS point analyses of the surrounding rock matrix, which show an absence of carbon, calcium, and nitrogen, but abundant silicon and aluminum. Full data for these EDS point analyses are presented in Data S1, S2. 


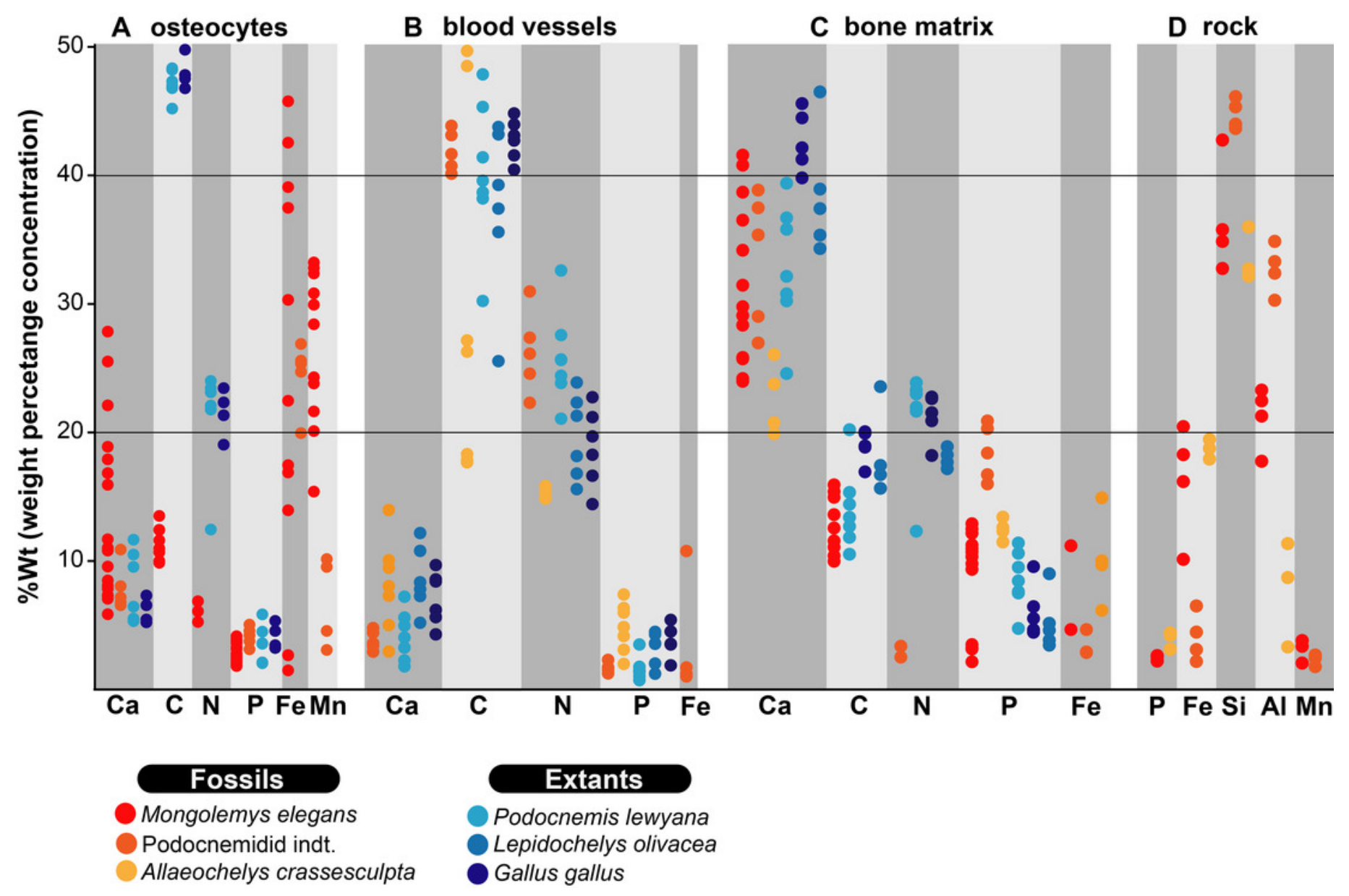




\section{Figure 3}

Figure 3. Fossil osteocytes-like from Mongolemys elegans (IGM-90/42).

(A-F) Isolated (post-demineralization) osteocytes-like viewed under transmitted light microscopy $(A, C, E)$ and polarized light microscopy $(B, D, F)$, showing low to moderate birefringence. All photographs taken with a 100X-oil immersion objective lens. 

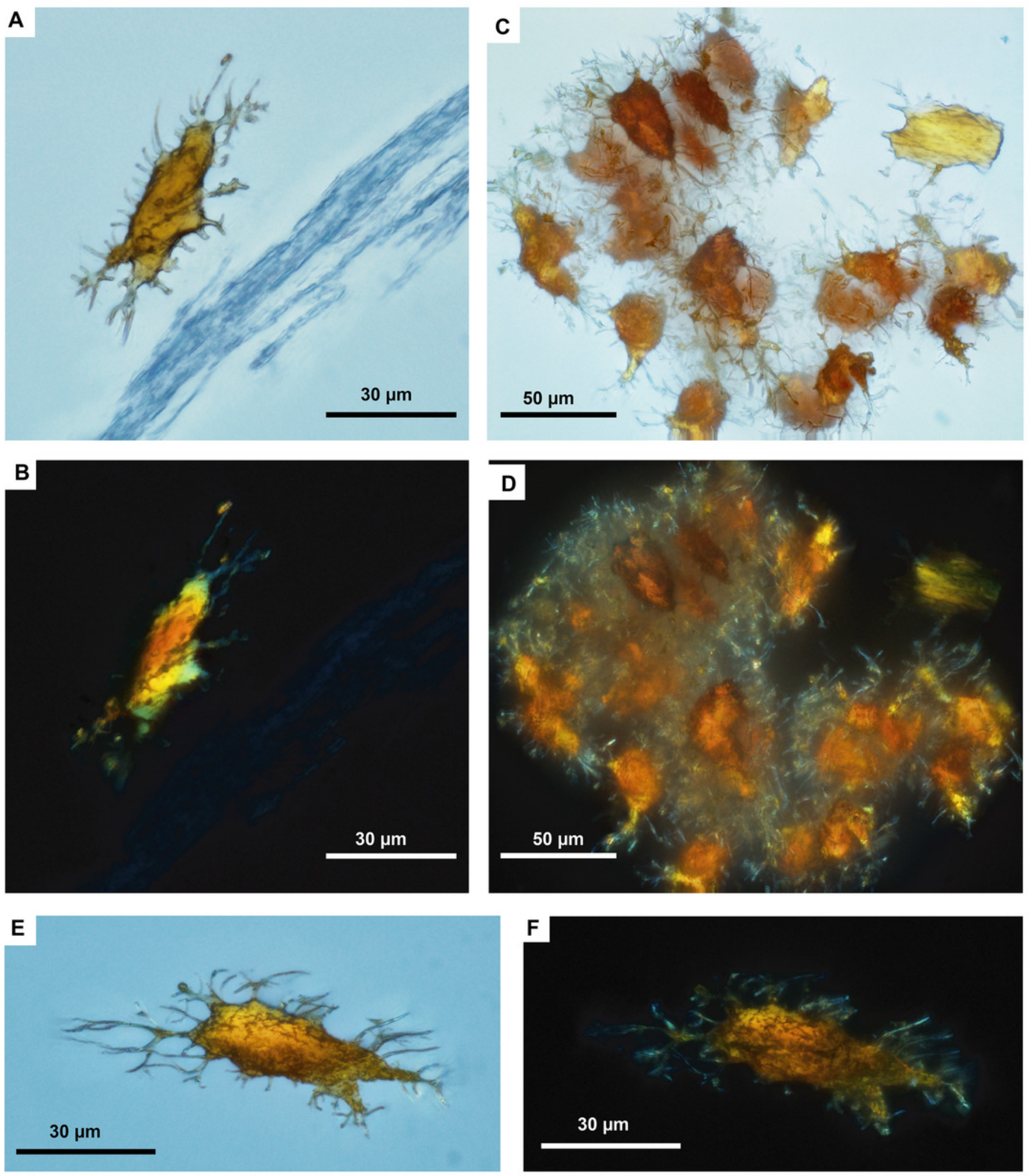


\section{Figure 4}

Figure 4. SEM/EDS analyses of Allaeochelys crassesculpta (SMF ME 2449) bone

(A-D) Micrographs of two Haversian canals, in which (B, D) show the blood vessels-like outlined in red, and osteoblasts-like outlined in green in. Measurements of the width of a blood vessel-like width, wall thickness, and osteoblast-like diameters are shown in (D). (E-G) Micrograph (E) and EDS elemental maps (F-G) of one of the blood vessels-like. (H) Elemental intensities for point 3 (blood vessel-like) shown in (E), showing it to be rich in carbon and nitrogen. (I) Elemental intensities for point 5 (bone matrix) shown in (E), showing an abundance of calcium, phosphorus, and iron, and absence of carbon and nitrogen. (J) Bone fragment placed in the SEM holder. (K) Micrograph showing a blood vessel-like embedded in the bone matrix, from the yellow region indicated in (J). (L) Close-up micrograph of the blood vessel-like shown in the red rectangle in (K). (M) Elemental intensities for point 3 (blood vessel-like) shown in (L), showing a high amount of carbon. (N) Elemental maps of the blood vessel-like shown in (L), indicating a high amount of carbon and nitrogen, these elements are absent in the surrounding bone matrix, which is composed mainly of calcium and phosphorus. (O-Q) Micrograph and EDS elemental maps of a bone margin in contact with rock matrix, the latter of which exhibits relatively higher amount of aluminum and absence of calcium, phosphorus, and iron. Full data for these EDS point analyses are presented in Data S1, S2. 

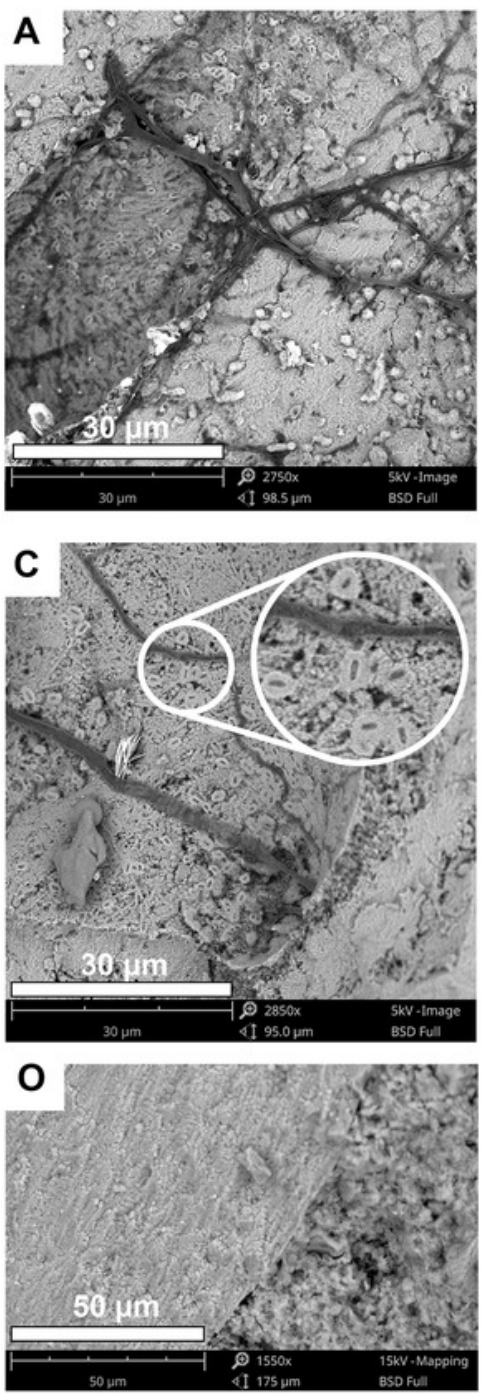

Q

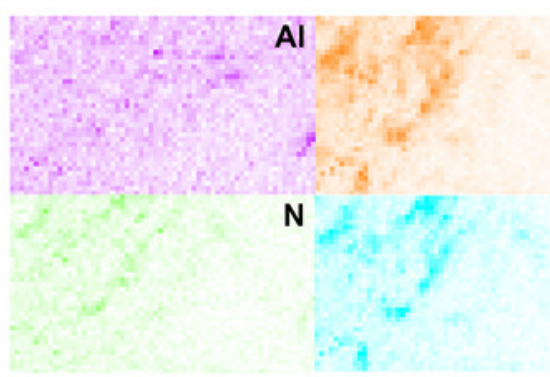

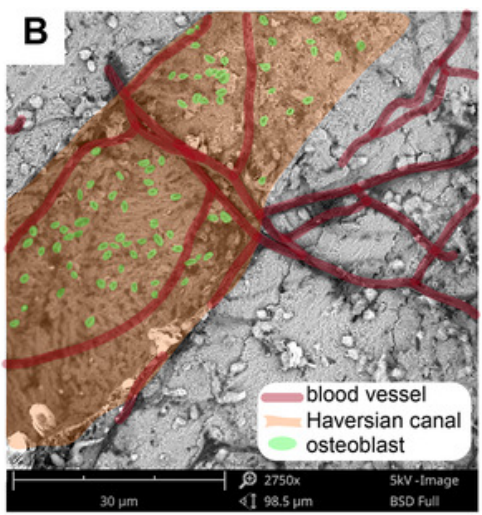
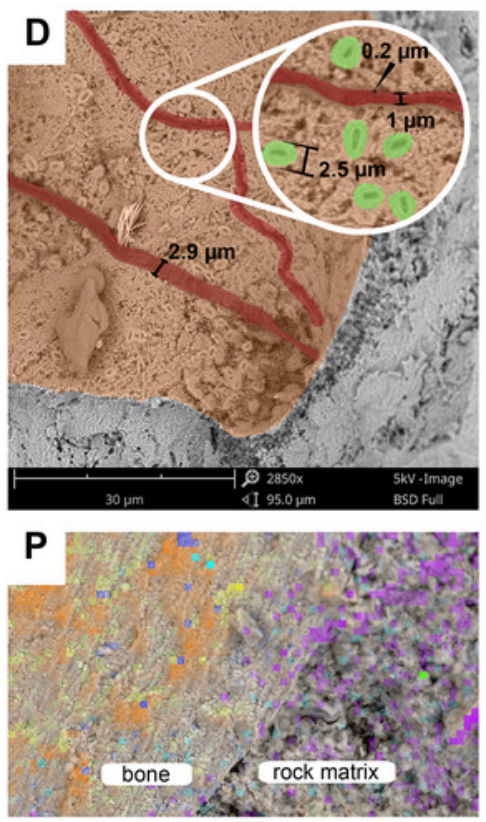

$\mathrm{Ca}$

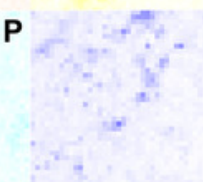

0
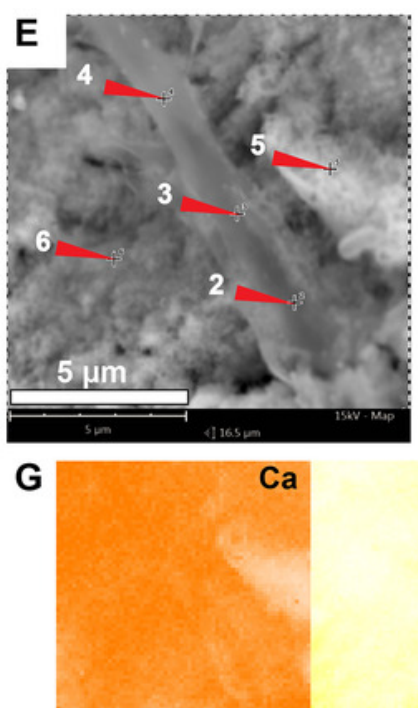

\section{H Point 3}

Element Atomic \%Weight \% Stoich.\%

$\begin{array}{lrrrl}\mathrm{O} & 50.69 & 43.04 & & \mathrm{O} \\ \mathrm{Ca} & 8.26 & 17.57 & 16.75 & \mathrm{C} \\ \mathrm{C} & 18.4 & 11.73 & 37.32 & \mathrm{Fe}\end{array}$

$\begin{array}{lrrrr}\mathrm{C} & 18.4 & 11.73 & 37.32 & \mathrm{Fe} \\ \mathrm{N} & 14.98 & 11.14 & 30.39 & \mathrm{Fe} \\ \mathrm{P} & 5.12 & 8.41 & 10.38 & \mathrm{P}\end{array}$

$\begin{array}{lllr}\mathrm{P} & 5.12 & 8.41 & 10.38 \\ \mathrm{Fe} & 1.55 & 4.59 & 3.14\end{array}$

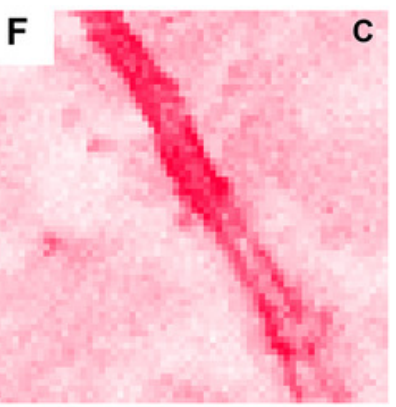

$\mathrm{Fe}$

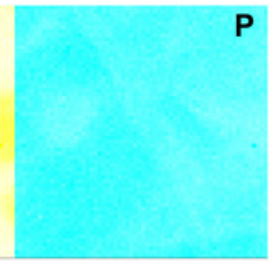

I Point $\mathbf{5}$

Element Atomic \% Weight \% Stoich. \% $74.31 \quad 52.3$

$\begin{array}{lll}11.42 & 20.14-44.46\end{array}$ $\begin{array}{lllll}1.55 & 4.59 & 3.14 & & \end{array}$
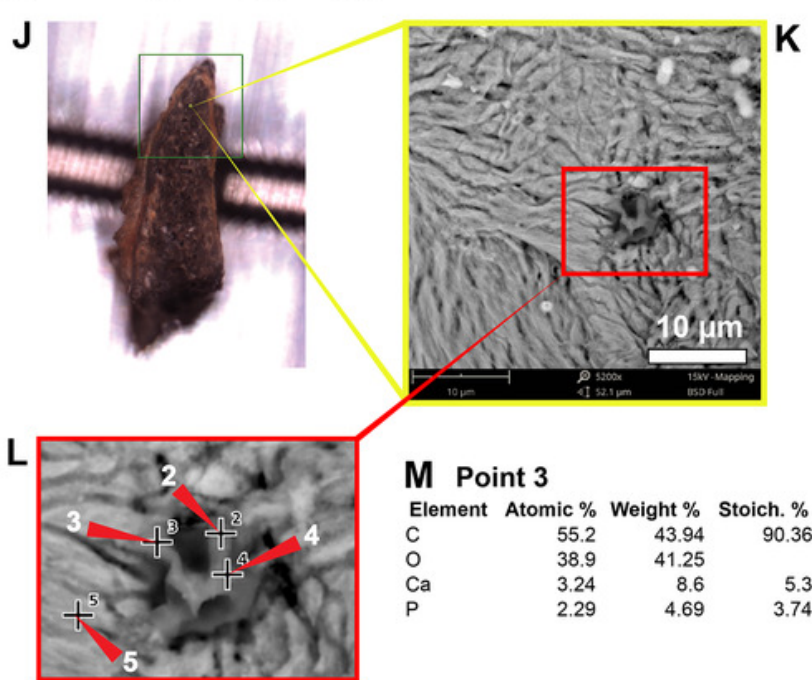

\section{$M$ Point 3}

Element Atomic \% Weight \% Stoich. \% $\begin{array}{lrrr}\text { C } & 55.2 & 43.94 & 90.36\end{array}$ $\mathrm{Ca}$

$\begin{array}{rrr}38.9 & 41.25 & \\ 3.24 & 8.6 & 5.3 \\ 2.29 & 4.69 & 3.74\end{array}$

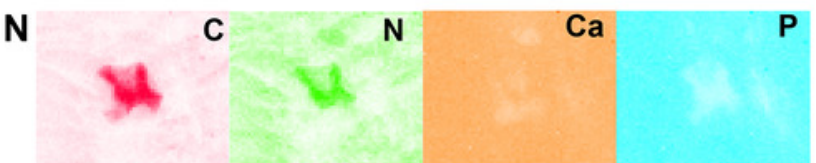




\section{Figure 5}

Figure 5. SEM/EDS analyses of podocnemidid indet. (UR-CP-0043) bone.

(A) Bone sample mounted in the SEM holder. (B-C) Micrograph and EDS element maps of one of the blood vessels-like embedded in the bone matrix, showing high amounts of carbon and nitrogen, a moderate amount of silicon; this differs from the bone matrix, which is dominated by calcium and phosphorus. (D) Elemental intensities for point 2 (blood vessel-like) shown in (B). (E) Elemental intensities for point 5 (bone matrix) shown in (B), showing a high amount of calcium and phosphorus. (F-G) Micrographs showing an osteocyte- and blood vessel-like $20 \mu \mathrm{m}$ away from each other, both embedded in the bone matrix. (H) EDS element maps of the region shown in $(F)$, the blood vessel-like exhibits high amounts of carbon and nitrogen, and the osteocyte-like is richer in iron but lacks significant carbon and nitrogen. (I) Elemental intensities for point 2 (blood vessel-like) shown in (F). (J) Elemental intensities for point 7 (osteocyte-like) shown in (F). (K) An isolated bone fragment after four days of demineralization, viewed under transmitted light microscopy (at 20x). (L) Close-up of the red rectangle region shown in (K), under polarized light microscopy (at 40x), showing darker osteocyte-like adjacent to where dendritic pyrolusite mats. (M) Close-up of the red rectangle region shown in (L) (at 100x), showing the dendritic pyrolusite and some of the osteocyteslike in detail. Full data for these EDS point analyses are presented in Data S1, S2. 

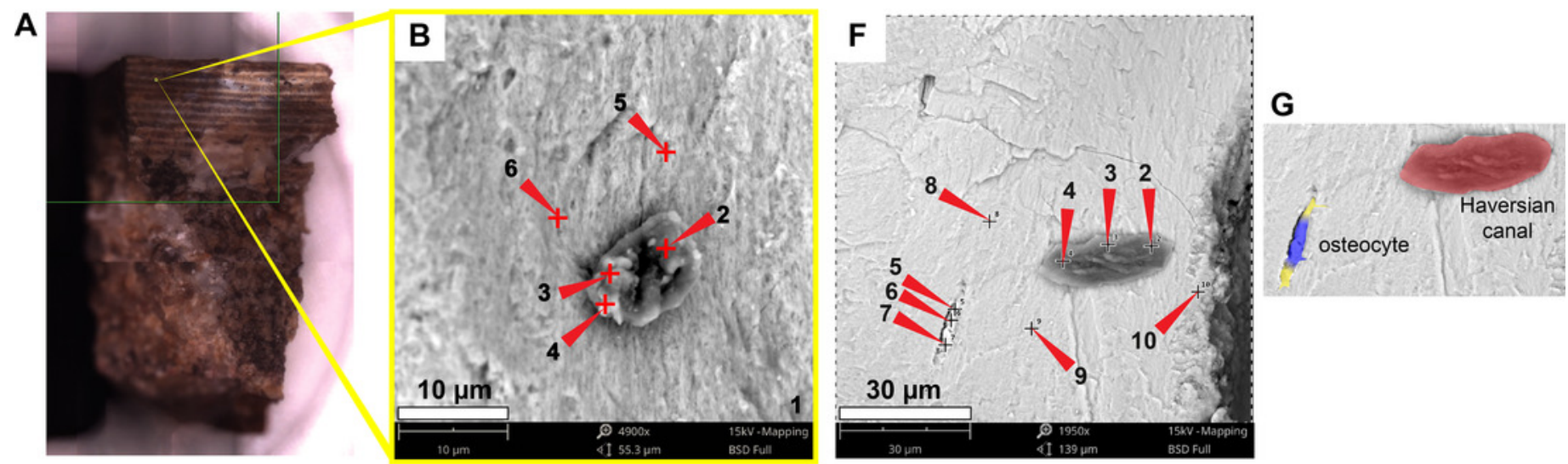

C

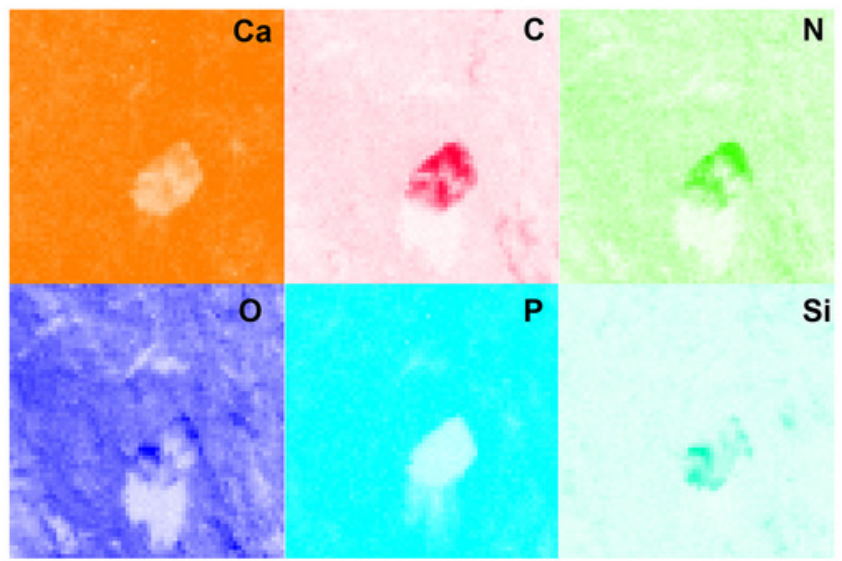

D Point 2

\section{E Point 5}

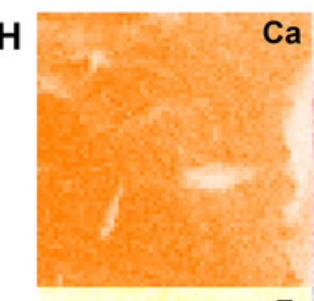

N

$\begin{array}{lrrrlrrr}\text { Element } & \text { Atomic \% } & \text { Weight \% } & \text { Stoich. \% } & \text { Element } & \text { Atomic \% } & \text { Weight \% } & \text { Stoich. \% } \\ \mathrm{C} & 65.85 & 55.52 & 94.49 & \mathrm{O} & 69.85 & 49 & \\ \mathrm{O} & 30.31 & 34.04 & & \mathrm{Ca} & 18.05 & 31.72 & 59.87 \\ \mathrm{Ca} & 1.52 & 4.28 & 2.19 & \mathrm{P} & 10.25 & 13.92 & 34 \\ \mathrm{Si} & 0.9 & 1.78 & 1.3 & & & & \\ \mathrm{P} & 0.78 & 1.69 & 1.11 & & & & \end{array}$

\section{Point 2}

Element Atomic \% Weight \% Stoich. \% $\begin{array}{llrr}\mathrm{C} & 40.53 & 31.91 & 51.49 \\ \mathrm{~N} & 30.89 & 28.36 & 39.23\end{array}$ a

C

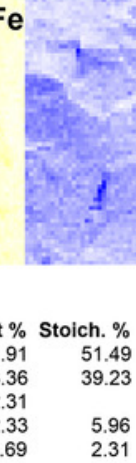

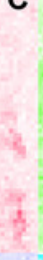

o

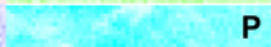

K

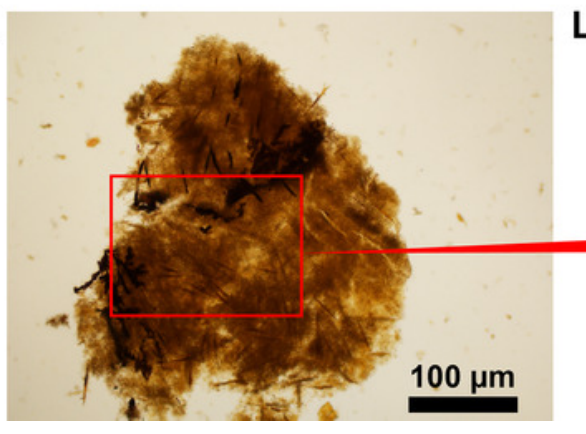

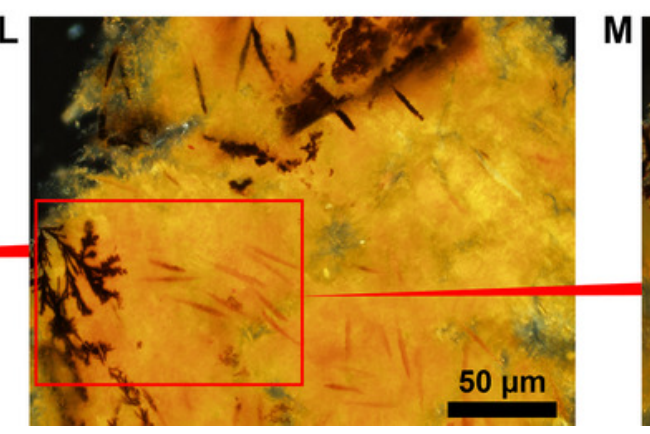
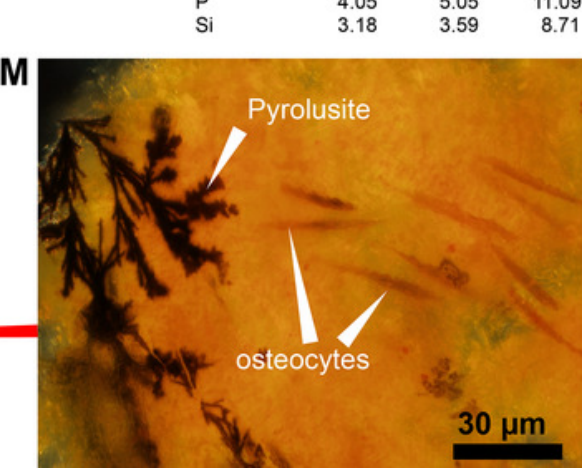


\section{Figure 6}

Figure 6. SEM/EDS analyses of the extant turtle and chicken bones.

(A) Bone fragment of Podocnemis lewyana in the SEM holder. (B-C) Micrograph and EDS element maps of osteocytes embedded in the bone matrix, showing high amounts of carbon and nitrogen; this differ from the bone matrix, which is dominated by calcium and phosphorus. (D) Elemental intensities for point 3 (osteocyte) shown in (B). (E) Elemental intensities for point 4 (bone matrix) shown in (B). (F) Micrograph of one of the Volkmann canals and a blood vessel system in the sample of $P$. lewyana. (G) Close-up of the Volkmann canal wall and blood vessel system (outlined in red) P. lewyana. (H) Bone fragment of Lepidochelys olivacea in the SEM holder. (I) Micrograph of a region of the cancellous bone shown in the yellow rectangle in (H). (J-K) EDS composite (J) and individual elemental (K) analyses of the bone region shown in (I). (L) Elemental intensities for point 2 (blood vessel) shown in (I), showing high amount of carbon and nitrogen. (M) Elemental point values for point 5 (bone matrix) shown in (I), showing high amounts of calcium and carbon. (N) Bone fragment from a femur of Gallus gallus in the SEM holder. (O) Micrograph of the bone region shown in the yellow rectangle in $(\mathrm{N})$, showing osteocytes embedded in the bone matrix. $(\mathrm{P})$ EDS elemental maps of one of the osteocytes (in the red rectangle) shown in (O), showing a high amount of carbon within the cell. Full data for these point analyses are presented in Data S1, S2. 


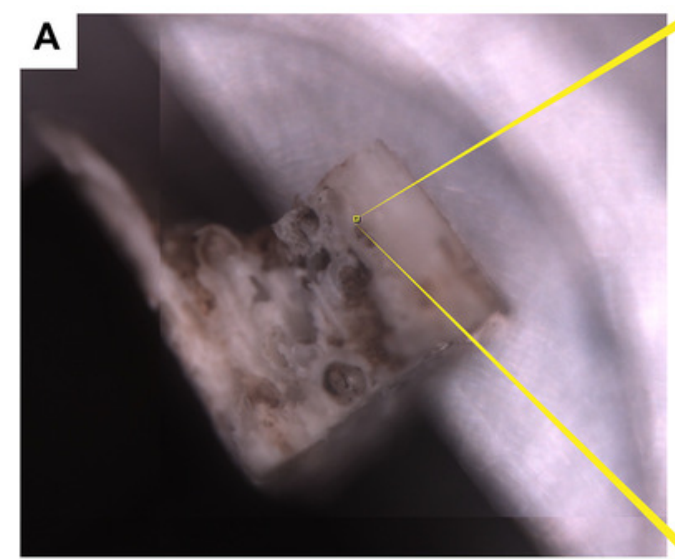

C

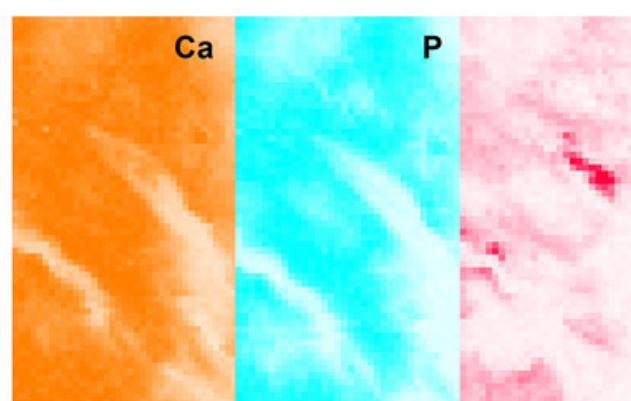

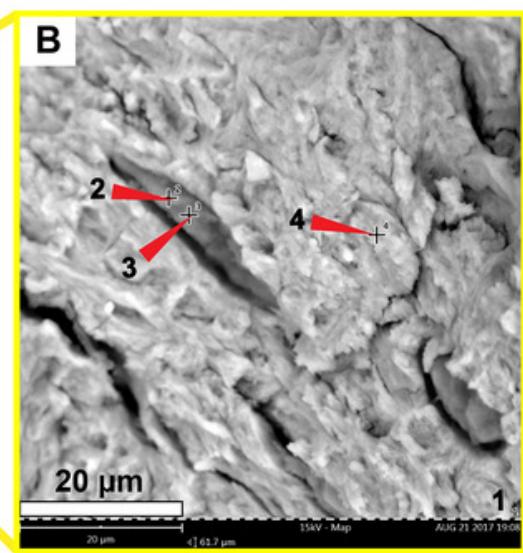

c

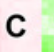

\section{E Point 4}

Element Atomic \% Weight \% Stoich. \% $\begin{array}{llll}\text { C } & 55.48 & 39 & 79.16\end{array}$ $\begin{array}{llrl}\mathrm{C} & 55.48 & 39 & 79.16 \\ \mathrm{Ca} & 12.22 & 28.65 & 17.43\end{array}$ $\begin{array}{lrrr}\mathrm{Ca} & 12.22 & 28.65 & 17.43 \\ \mathrm{O} & 29.92 & 28.02 & \\ \mathrm{P} & 2.39 & 4.33 & 3.41\end{array}$
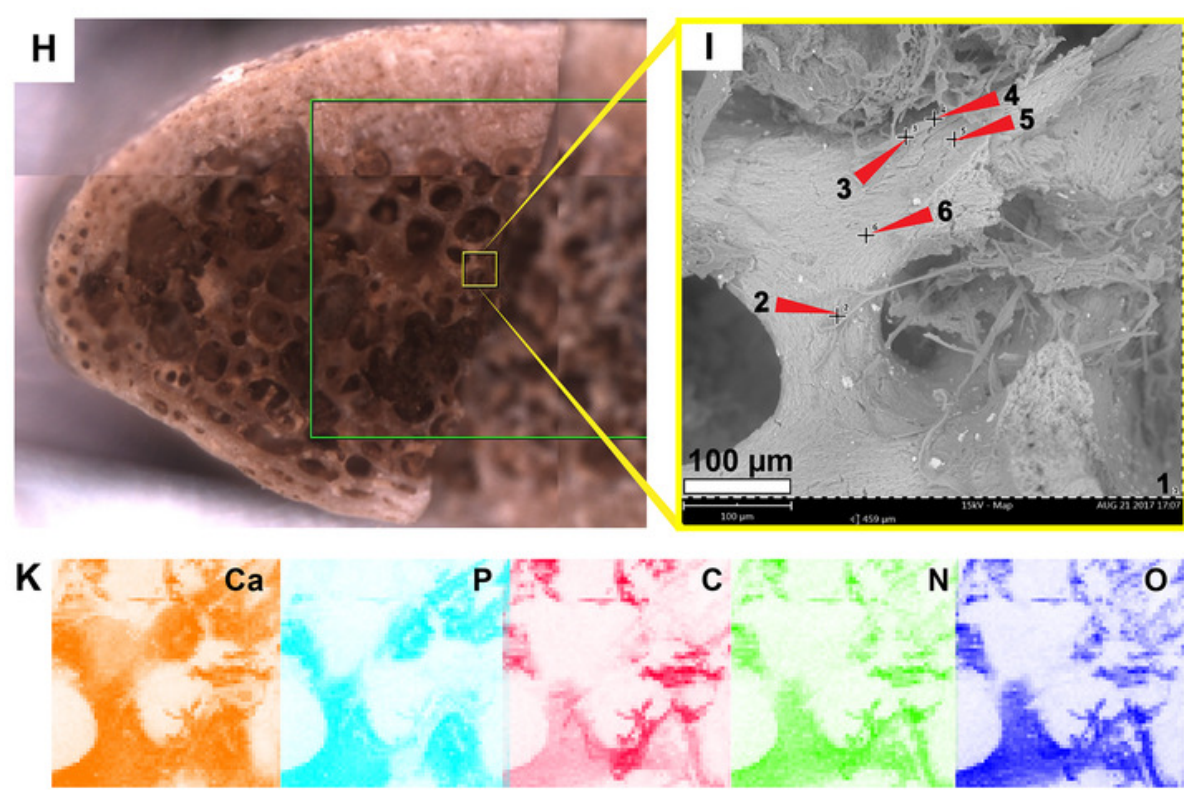

$P=k^{*} c$

$\begin{array}{lrrr}\text { Element } & \text { Atomic \% } & \text { Weight \% } & \text { Stoich. \% } \\ \mathrm{Ca} & 19.56 & 39.47 & 30.72\end{array}$

$\mathrm{C}$
$\mathrm{O}$
$\mathrm{N}$
$\mathrm{C}$
$\mathrm{P}$

$\mathrm{O}$
$\mathrm{N}$
$\mathrm{C}$
$\mathrm{P}$

19.56

$36.34 \quad 29.28$

กาง

$\mathbf{N}$
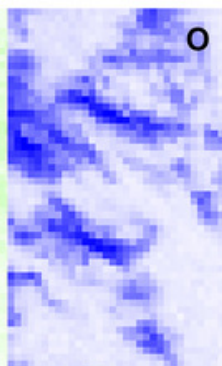

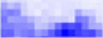

$5.8 \quad 35.2$

$\begin{array}{rr}1.65 & 30.25 \\ 3.8 & 3.83\end{array}$

L Point 2

Element Atomic \% Weight \% Stoich. \%

$\begin{array}{llll}\text { C } & 53.67 & 43.52 & 69.25 \\ \text { O } & 22.49 & 24.29 & \end{array}$

$\begin{array}{llll}\mathrm{O} & 22.49 & 24.29 & \\ \mathrm{~N} & 17.88 & 16.91 & 23.07\end{array}$

$\begin{array}{lrrr}\mathrm{N} & 17.88 & 16.91 & 23.07 \\ \mathrm{Ca} & 2.97 & 8.03 & 3.83 \\ \mathrm{P} & 1.85 & 3.87 & 2.39\end{array}$

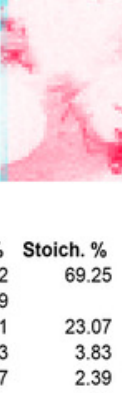

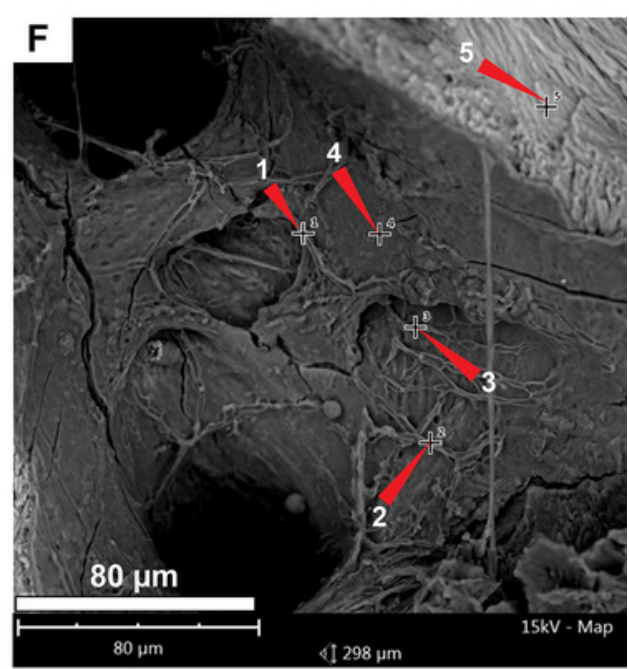
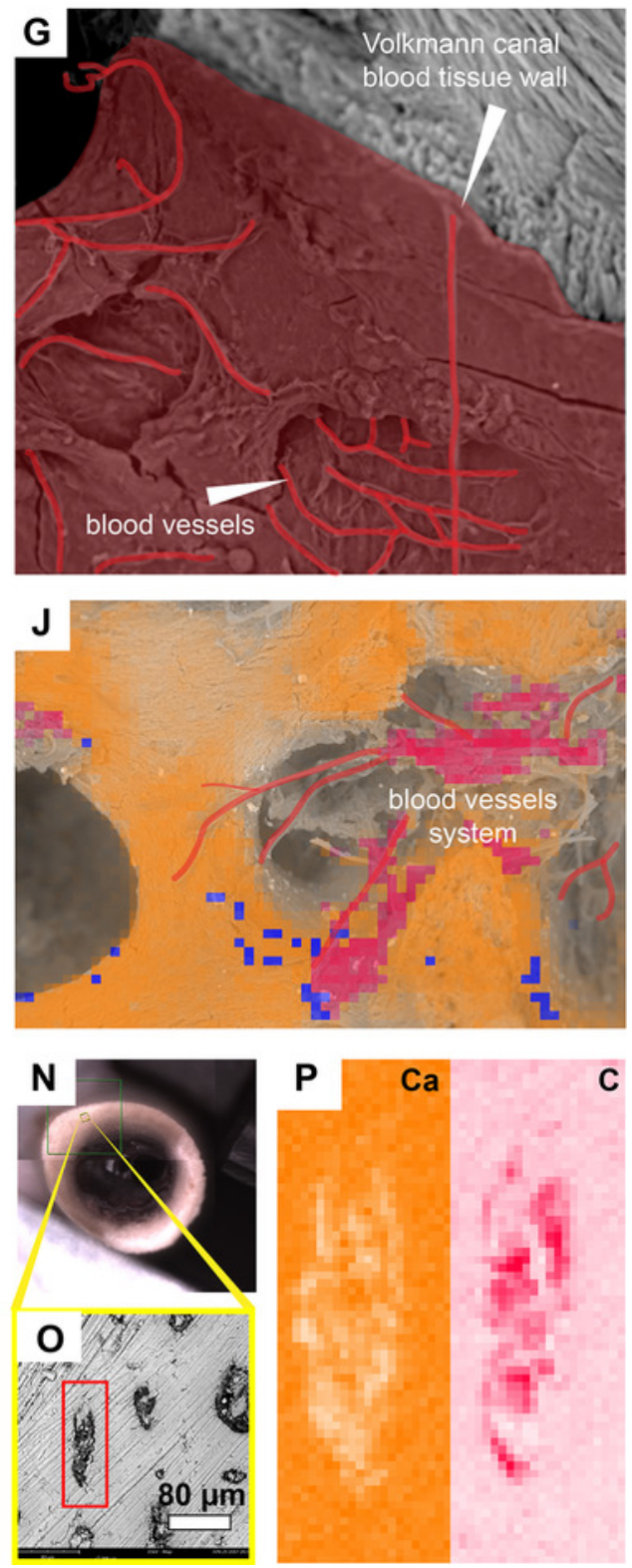